\title{
Narrative review of: risk stratification and implantable cardioverter-defibrillator therapy in adults with congenital heart disease
}

\author{
Julia Köbe ${ }^{1}$, Kevin Willy ${ }^{1}$, Lars Eckardt ${ }^{1}$, Helmut Baumgartner ${ }^{2}$, Kristina Wasmer ${ }^{1}$ \\ ${ }^{1}$ Department of Cardiology II - Electrophysiology, University Hospital Muenster, Muenster, Germany; ${ }^{2}$ Department of Cardiology III, Adult \\ Congenital and Valvular Heart Disease, University Hospital Muenster, Muenster, Germany \\ Contributions: (I) Conception and design: J Köbe, L Eckardt, H Baumgartner, K Wasmer; (II) Administrative support: J Köbe; (III) Provision of study \\ materials or patients: J Köbe, K Willy, K Wasmer; (IV) Collection and assembly of data: J Köbe, K Willy; (V) Data analysis and interpretation: J \\ Köbe, K Wasmer; (VI) Manuscript writing: All authors; (VII) Final approval of manuscript: All authors. \\ Correspondence to: PD Dr med. Julia Köbe. Klinik für Kardiologie II, Rhythmologie, Universitätsklinikum Münster, Albert-Schweitzer-Campus 1, \\ D-48149 Münster, Germany. Email: koebeju@ukmuenster.de.
}

\begin{abstract}
Fortunately, the population of adults with congenital heart disease (ACHD) is growing due to improved operation techniques. Life expectancy is continuously rising, nevertheless, sudden cardiac death is one of the leading causes of mortality in ACHD late after initial diagnosis. Risk stratification in ACHD remains challenging as large study results are missing, congenital defects and operation methods differ considerably between individual patients and results from acquired heart diseases are often not conferrable. The purpose of this narrative review is to objectively summarize the current knowledge on arrhythmogenic risk of ACHD and to give an overview on implantable cardioverter-defibrillator (ICD) therapy in this collective. Remarkable progress has been made in electrophysiological understanding of critical areas of slow conduction especially in patients with Tetralogy of Fallot (ToF). In patients with transposition of the great arteries after atrial baffling (Mustard/Senning procedure) atrial arrhythmias play a crucial role in sudden cardiac death. ICD therapy in ACHD may pose special technical challenges due to limited access for intracardiac leads. The introduction of the totally subcutaneous ICD improved therapeutic options for ACHD especially when contraindications for transvenous leads are present. Risk stratification in ACHD has to be seen as a team approach, requires thorough understanding of congenital heart defects and the operation techniques and needs unconventional technical approaches in some cases.
\end{abstract}

Keywords: Adults with congenital heart diseases (ACHD); ventricular arrhythmia, risk stratification, implantablecardioverter-defibrillator

Submitted Jul 11, 2020. Accepted for publication Jan 13, 2021.

doi: $10.21037 / \mathrm{cdt}-20-633$

View this article at: http://dx.doi.org/10.21037/cdt-20-633

\section{Introduction}

As the number of adults with congenital heart diseases (ACHD) is continuously rising and more patients reach adulthood ventricular arrhythmias and sudden cardiac death are of growing clinical relevance. The purpose of this narrative review is to provide an overview over risk stratification for ventricular arrhythmias in ACHD and outline progress in ablation strategies. Besides, current defibrillator techniques are reviewed and placed into perspective. Risk stratification for sudden cardiac death is of major importance in counselling ACHD patients for clinical cardiologists decades after first diagnosis and has to be updated regularly as operation techniques have changed over time.

It is estimated, that approximately $20-25 \%$ of deaths in ACHD occur due to ventricular arrhythmias (1). Risk 
stratification in these patients is challenging as data and large studies are almost completely missing and surgical lesions and structural alterations are very individual and often not conferrable. Confounding factors facilitating arrhythmias exist in these patients, ranging from accessory pathways, coronary artery abnormalities to incisions, fibrosis, prosthetic material and/or pressure/volume overload. Due to the differences and complexity in pathophysiological arrhythmia substrates, knowledge of common acquired adult heart diseases cannot be directly transferred to ACHD. Due to changes of operation techniques risk factors in older series may no longer be transferable to more recent cohorts. Recommendations for implantable cardioverter-defibrillator (ICD) implantation in the current guidelines only recognize approximately $40 \%$ of sudden cardiac death cases in ACHD, so that the discriminative ability of current recommendations is relatively low (2).

Anyhow, management of arrhythmias in ACHD has made remarkable progress with current electrical device therapy and ablation strategies being expanded to complex congenital heart diseases. 3D-Mapping techniques and implementation of imaging into mapping systems offer a better understanding of arrhythmia mechanisms in ACHD. Besides, a variety of electrical devices offer adequate and physiological pacing and prevention of sudden cardiac death. Especially, the introduction of the totally subcutaneous implantable cardioverter defibrillator $\left(\mathrm{S}-\mathrm{ICD}^{\circledR}\right)$ improved therapeutic options for ACHD with limited transvenous access or with contraindications for transvenous leads in case of right-to-left shunting (3).

Counselling ACHD in terms of individual risk for life threatening arrhythmias requires a deep understanding of the underlying structural alterations, surgical techniques and prognosis. Therefore, risk stratification in ACHD has to be understood as a team approach between electrophysiologist, ACHD specialist, pediatric cardiologist and surgeon.

The key questions attended to in this review are: (I) quantification of the specific arrhythmogenic risk for the most common congenital heart diseases, (II) risk markers and the role of electrophysiological testing for individual congenital heart defects and (III) technical aspects of conventional transvenous and subcutaneous ICD therapy in ACHD. We present the following article in accordance with the Narrative Review reporting checklist (available at http://dx.doi.org/10.21037/cdt-20-633).

\section{Methods}

We performed a MEDLINE search from 1995 to June 2020 using the words listed in the key words section of this review. Case reports were excluded from the review. Additionally, we reviewed the literature cited in the current guidelines for arrhythmias in ACHD patients (www. escardio.org).

\section{Discussion}

\section{General aspects of ventricular arrhythmias in ACHD}

Overall prevalence of ACHD is estimated to be 4 by 1,000 (4) with distribution between different defects as outlined in Table 1. It is estimated that the population of ACHD compromises 1.2 million in Europe (5). Mortality of ACHD has shifted from infancy towards adulthood with an increase of age at death by more than 20 years over the last decades (6). A large national registry reported 9.2\% deaths among 2,596 ACHD over a period of 3.6 years with heart failure being the most common cause $(27.6 \%)$ followed by sudden cardiac death (23\%) (7). In a modern cohort of a large British tertiary center of 6,969 ACHD overall mortality rate was lower with $0.72 \%$ per patient year (8). Comparably, a Dutch registry reported $2.8 \%$ of deaths during a mean follow-up of 3.5 years (9). Sudden cardiac death rates vary between $7 \%$ and $19 \%$ and heart failure was the predominant reason for death in ACHD in all recent reports. Reduced sudden cardiac death rates in tertiary center patients probably reflect the improved outcome of ACHD in specialized centers.

Cause of death differs considerably between individual congenital heart defects with sudden cardiac death being the leading cause in patients with transposition of the great arteries with an intraatrial baffle (TGA) and Tetralogy of Fallot (ToF) whereas heart failure remains the major cause of death in patients with Eisenmenger syndrome and univentricular hearts (UVH) (9). However, substantial differences can be seen between published results. For example, no sudden cardiac death occurred in patients with Ebstein anomaly in a British cohort $(\mathrm{n}=153)$ whereas more than one third died of arrhythmias in the Dutch cohort $(\mathrm{n}=117)(8,9)$. One of the fundamental key points is that risk stratification differs considerably between congenital heart defects and has to be performed individually and lesion specific. 
Table 1 Birth prevalence, standardized mortality ratio and estimated prevalence of ventricular arrhythmias for most common congenital heart diseases [modified from $(1,4)$ ]

\begin{tabular}{lccc}
\hline $\begin{array}{l}\text { Underlying congenital heart } \\
\text { disease }\end{array}$ & $\begin{array}{c}\text { Distribution of } \\
\text { congenital heart defects } \\
\text { (per 100,000 births) }\end{array}$ & $\begin{array}{c}\text { Mortality ratio standardized } \\
\text { (in relation to sex- and age-matched } \\
\text { general population) }\end{array}$ & $\begin{array}{c}\text { Estimated prevalence } \\
\text { of ventricular arrhythmias }\end{array}$ \\
\hline Tetralogy of Fallot & 0.34 & 2.34 & $10-15 \%$ \\
TGA, Mustard/Senning & 0.31 & 2.61 & $7-9 \%$ \\
TGA, arterial switch & $0.02-0.05$ & 4.8 & $1-2 \%$ \\
ccTGA & 0.04 & 1.86 & $2-3 \%$ \\
Atrioventricular septal defect & 0.07 & 3.30 & $2-3 \%$ \\
Ebstein anomaly & $0.01-0.04$ & 23.40 & $5 \%$ \\
Single ventricle & 1.64 & 1.13 & Very low \\
Atrial septal defect & 2.62 & 1.36 & Very low \\
Ventricular septal defect & 0.87 & 0.42 & Very low \\
Ductus arteriosus & & & \\
\hline
\end{tabular}

TGA, transposition of the great arteries; ccTGA, congenitally corrected transposition of the great arteries.

\section{Risk stratification in selected congenital heart defects}

\section{ToF}

ToF is the most common cyanotic congenital heart defect (10) with increasing prevalence due to improved and earlier surgical repair. The complex comprises a ventricular septal defect, overriding aorta, right ventricular outflow tract obstruction (infundibular, valvular or both) and a consecutive right ventricular hypertrophy. A total repair usually includes closure of the ventricular septal defect, resection of the outflow tract obstruction frequently including patch enlargement. Surgical approach has considerably changed from access via ventriculotomy to abandonment of ventricular incisions and avoidance of pulmonary regurgitation. Nowadays, it is well known that the surgery has considerable impact on later arrhythmias in ToF patients. One third of late deaths in ToF patients occurs due to ventricular arrhythmias (11) with a prevalence of $2 \%$ to $8 \%$ (Table 1 ). The predominant ventricular tachycardia in $\mathrm{ToF}$ is monomorphic ventricular tachycardia (81\%) with short cycle lengths (range, 182-264 bpm) $(12,13)$.

Unfortunately, no single risk factor has sufficient power to predict ventricular arrhythmias in ToF beyond severely reduced left ventricular function, so that combination of several parameters has to be considered (14). In retrospective cohorts a number of non-invasive and invasive risk factors for late ventricular arrhythmias has been found. The QRS-width in 12-lead ECG reflects the degree of right ventricular enlargement and impairment. A QRS-width $>180 \mathrm{msec}$ and a rapid progression of QRSwidth ( 3 msec per year) have been correlated with sudden cardiac death and ventricular tachycardia (15). Though, QRS fragmentation revealed to be more sensitive in a large Dutch ToF cohort and was superior to QRS width (16). Characterization of right and left ventricular substrate, function and volumes has substantially been improved by cardiac MRI. Right ventricular scarring in MRI seems to be a strong and independent predictor for arrhythmias even in patients with narrower QRS complexes but cutoff values are still scarce (17). Although evaluation of the right ventricle remains essential in ToF risk stratification, there is emerging evidence that the left ventricle and the interaction between both ventricles also play a substantial role (18). Besides, a prior palliative shunt and older age at total ToF repair ( $>5$ years) have been identified as strong risk factors for later arrhythmias (11). The predictive value of non-sustained VT in ToF patients is conflicting. In a retrospective Dutch cohort with ICD for primary prevention non-sustained symptomatic VT were the sole predictor of appropriate ICD interventions (19) emphasizing the role of patients' symptoms (syncope, dizziness, rapid palpitations) in risk assessment.

In terms of invasive risk stratification inducibility by programmed ventricular stimulation showed a 2.6 fold risk 
of later arrhythmia occurrence (13) in a retrospective ICD ToF collective. Nevertheless, inducibility of ToF patients differs considerably between study cohorts and does not reliably correlate with non-invasive risk factors (20) reflecting the low sensitivity of programmed ventricular stimulation on the one hand and differences in stimulation protocols and sites on the other hand. Another invasive parameter for risk stratification is left ventricular enddiastolic pressure (LVEDP) with an almost 5-fold risk for later ventricular arrhythmias if LVED is $\geq 12 \mathrm{mmHg}$ (13) drawing a bow to the mentioned relevance of the left ventricular function. Khairy et al. aimed at developing a risk score employing six clinical variables: prior palliative shunt, inducibility at electrophysiologic study, QRS duration $\geq 180 \mathrm{msec}$, ventricular incision, non-sustained ventricular tachycardia, LVEDP $\geq 12 \mathrm{mmHg}$ (13). The score has been clinically widely accepted reflecting the wish of easy risk stratification tools in ToF but has not been implemented into clinical guidelines, yet $(21,22)$. Of note, the score does not incorporate modern tools like MRI parameters and is often incomplete as surgical protocols (e.g., knowledge on ventricular incision) are missing (23).

In patients with $\mathrm{ToF}$ the pathophysiologic substrate for ventricular arrhythmias is best characterized of all CHD. Modern mapping options and especially 3-dimensional electroanatomical mapping techniques have added substantial progress to visualization of macro-reentry circuits as underlying mechanism for monomorphic ventricular tachycardias in ToF. Areas of surgical incisions and patch material serve as conduction blocks allowing arrhythmogenic isthmuses and reentry circuits of ventricular tachycardias. Electrophysiologists of Leiden University have nicely identified four potential critical isthmuses in repaired ToF (24). Isthmus 1 (between tricuspid anulus and ventriculotomy/right ventricular anterior patch) and isthmus 3 (between pulmonary valve and ventricular septal defect) can be found in almost all ToF patients whereas a critical isthmus 2 (between pulmonary valve and ventriculotomy/right ventricular anterior patch) and isthmus 4 (between tricuspid anulus and ventricular septal defect) are only present in approximately one fourth of ToF patients (25). The areas of slow conduction can be identified during sinus rhythm, a more advantageous condition in ToF patients usually presenting with rapid and poorly tolerated ventricular tachycardias. Successful transection of slow conducting isthmuses seems to result in a very favorable outcome of ToF patients so that ablation of isthmuses may perhaps be a curative treatment and alternative to ICD therapy (26). However, sufficient data is still missing to generally resign from ICD implantation in ToF with spontaneous or inducible ventricular tachycardias (see this issue Wasmer et al.). Future research has to focus on long-term results of ablation strategies in ToF patients.

\section{Transposition of the great arteries (D-TGA)}

Patients born with transposition of the great arteries (D-looped ventricles, D-TGA) differ considerably dependent on the surgical technique. Until 1980s atrial baffling with atrial inflow correction (Mustard or Senning operation) for D-TGA was the only surgical approach leaving the right ventricle as lifelong systemic ventricle and the atrial level with the surgically created scars as substrate for arrhythmias. Surgery with direct switch of the arteries has changed late complications and risk for ventricular arrhythmias in D-TGA patients. Although the number of patients after Mustard/ Senning procedure is declining as this operation technique has been abandoned patients after baffling of the atrium bear high sudden cardiac death risk (Table 1).

The mode of operation for atrial inflow correctioneither with the native atrial septum (Senning) or with artificial material (Mustard) - seems not to be relevant for later ventricular arrhythmias (27). After Mustard or Senning repair several studies revealed supraventricular tachyarrhythmias as being predictive for sudden cardiac death (28-30). Atrial flutter is very common in D-TGA patients after baffling with rates of up to $60 \%$ during long-term follow-up $(31,32)$. The initial suspicion that bradycardias in these patients are linked to sudden cardiac death did not come true as pacemaker implantations did not alter sudden cardiac death rates. In contrast, pacemaker implantation was associated with a higher mortality rate in a large cohort from Denmark and Sweden (27). It remains unclear whether the amount of ventricular stimulation leads to impaired ventricular function in D-TGA after pacemaker insertion or whether this circumstance is rather a marker than a cause of sudden cardiac death. Most of sudden cardiac death events occur during exercise and the predominant underlying arrhythmia is ventricular fibrillation. Episodical reports with pacemakers intended to overdrive-pacing of atrial tachycardias documented rapid ventricular response to atrial arrhythmias leading to ventricular tachycardias and fibrillation (33). In a multicenter study including 37 D-TGA patients implanted with an ICD 50\% of appropriate shocks were preceded by supraventricular arrhythmias and a lack of $ß$-blocker was the sole independent predictor for appropriate shocks (34). It has to be emphasized that TGA 
patients after Mustard/Senning repair should therefore receive a $ß$-blocker whenever possible. Of note, newer autopsy results provide histopathological evidence of myocardial ischemia probably due to inefficient coronary circulation and increased oxygen consumption in the hypertrophic structural right ventricle provoked by rapid atrial arrhythmias or exertion (35). In contrast to ToF, programmed ventricular stimulation does not seem to be predictive in D-TGA patients (34) although published series are small. A study evaluating D-TGA outcome after Mustard procedure found a QRS duration $>140 \mathrm{msec}$ to have a 10-fold higher risk for ventricular tachyarrhythmias reflecting the impaired systemic ventricular function (36). In conclusion, advice for a defibrillator for primary prevention has to be based on an individual decision and is not well defined. Atrial arrhythmias, surgery at an older age (median 53 months versus 14 months) and systemic ventricular function should also be taken into account. Besides, after modern operation technique with arterial switch sudden death is an infrequent event with a prevalence of approximately $1 \%$. These arrhythmic deaths are attributed to unnoticed coronary events in the denervated coronary arteries or to rare events of ventricular dysfunction (37).

\section{Congenitally corrected transposition of the great arteries (ccTGA, L-TGA)}

Patients with congenitally corrected transposition of the great arteries (ccTGA, L-TGA) do not need early surgery after birth as pulmonary and systemic circuits are unimpaired. Nevertheless, the right ventricle serves as lifelong systemic ventricle. CcTGA patients have an increased frequency of conduction abnormalities ('fragile' and dual $\mathrm{AV}$-node), accessory pathways and tricuspid valve abnormalities (38). Evidence on risk markers for sudden cardiac death are scarce. Several series have reported concomitant malformations (e.g., ventricular septal defect) or tricuspid valve regurgitation and systemic ventricular impairment as major underlying cause for sudden cardiac death $(39,40)$. Nevertheless, sudden cardiac death occurred mostly in patients without deterioration of the systemic ventricle in an Australian cohort reporting sudden cardiac death in $12 \%$ of ccTGA patients who were routinely followed by echocardiography and Holter ECG (38). Cardiac MRI for evaluation of the right ventricular function has proven to add valuable information in terms of risk stratification of ccTGA patients and seems to be superior to echocardiography (41). Likewise, there is evidence of disturbed perfusion of the subaortic right ventricle in
ccTGA patients (42).

\section{Single ventricle/univentricular conditions}

Univentricular conditions summarize a variety of congenital heart defects where biventricular repair is not possible as either the right or the left ventricular chamber is missing or hypoplastic. Due to the heterogeneity of malformations risk stratification for ventricular arrhythmias is mainly based on expert consensus and small series. The Fontan procedure is associated with a relevant long-term risk of atrial arrhythmias ranging from $10 \%$ to $50 \%(43,44)$ dependent on the operation technique [total pulmonary connection or atriopulmonary connection described in detail elsewhere (45)]. Atrial arrhythmias may be linked to ventricular arrhythmias and sudden cardiac death in this population as they are usually poorly tolerated (46). Even though patients with an extracardiac Fontan circulation have a lower risk for atrial arrhythmias the sudden cardiac death risk seems to be high reflecting that precise causes of late death in this collective still have to be investigated. Nevertheless, it has to be taken into account that overall survival rates of patients with an extracardiac conduit is higher (46). In terms of non-invasive risk stratification nonsustained ventricular tachycardias and ventricular ectopy are frequent in patients with univentricular conditions but have not shown a significant risk elevation for sudden cardiac death (47). In conclusion, patients with UVHs are particular challenging whenever the decision for a device-either pacemaker or implantable cardioverter defibrillator-has to be made (see section ICD therapy in ACHD).

\section{Ebstein anomaly}

There is little and conflicting evidence on sudden cardiac death risk in patients with Ebstein anomaly. Ebstein anomaly can present in a wide range of clinical severity in terms of both valve dysfunction, right ventricular function and surgical interventions. The largest retrospective study on Ebstein anomaly from the Mayo Clinic collective studied 986 patients over a mean follow-up time of 13 years. Pulmonic stenosis, elevated hemoglobin levels, syncope, and prior tricuspid valve surgery turned out to be independent predictors of sudden cardiac death (48).

\section{Ventricular septal defects}

Ventricular septal defects are the most common congenital heart malformations. The lesion may need surgical repair or may spontaneously resolve without interventions. Surgical repair can imply a suture or closure with different patch 
materials. Larger defects result in relevant shunts with consecutive increased pulmonary blood flow. A history of ventricular septal defect closure does not appear to elevate long-term mortality (49). Nevertheless, in the largest cohort of corrected ventricular septal defects from the Netherlands with a follow-up of 35 years $1 \%$ of sudden cardiac deaths were reported - 34 and 39 years after surgery, respectively (50). The role of critical isthmuses related to ventriculotomy or suture/patch material is yet unclear.

\section{ICD therapy in ACHD}

\section{General aspects}

ACHD represent a minority of all patients with ICDs. The role of ICD implantation for secondary prevention in ACHD is comparably evident as in other structural heart diseases and a Class I indication in current guidelines. Concerning primary prevention in ACHD no randomized controlled trials exist and indications for ICD are often extrapolated from other structural heart diseases or rely on retrospective analysis or expert opinion. However, an ICD is recommended in patients with systemic left ventricular impairment (ejection fraction $\leq 35 \%$ ), biventricular physiology and heart failure symptoms NYHA II/III (level of evidence IB) (1). Broader indications for primary prevention in ACHD patients pose specific problems as the prediction of individual arrhythmic risk is very difficult, competing risks for mortality are high, patients are young and the ICD itself may be associated with a considerable morbidity and mortality risk.

A literature review on ICD indications and outcome including 2,162 ACHD from 24 studies revealed a primary prevention indication in $50 \%$ of patients with $50 \%$ having ToF as underlying heart disease. Appropriate ICD interventions were high with $22.3 \%$ of patients with a primary prevention indication and $35.3 \%$ of patients with secondary prevention experiencing an ICD intervention for ventricular arrhythmias during a mean follow-up of 3.7 years (51). Other smaller studies have reported even higher appropriate shock rates of $50 \%$ in 2 years of follow-up (52). Mortality rates with an ICD in ACHD were comparable to those in the German ACHD registry (10\% versus $9.2 \%$, respectively) (7) but considerably lower than in studies including ischemic and non-ischemic cardiomyopathies (e.g., SCD-HeFT 22\%, follow-up 3.8 years) (53) probably reflecting the younger age of ACHD.

ICD therapy in ACHD seems to be associated with a high long-term complication rate. Almost 30\% of
ACHD implanted with an ICD experience device-related interventions and particularly lead-related problems over a mean follow-up of 3 years $(16,51,54)$. However, periprocedural complication rate seems to be low with $2.3 \%$ in-hospital complications reported in 3,000 ICD implantations although implantation technique require non-transvenous leads in 3\% of cases (55).

One of the key findings is that ICD therapy in young patients with congenital heart defects bears a substantial risk for inappropriate shocks. In a pediatric population $21 \%$ of patients experienced inappropriate ICD therapy mainly due to lead problems or supraventricular tachycardias over a study period of 12 years (56). A literature review of Vehmeijer et al. reported inappropriate ICD shock rates of $25 \%$ in 3.7 years although studies published from 2002 to 2014 were analyzed representing a different programming era (51). Tailored ICD programming incorporating recent algorithms, high detection rates and telemetric observation reduces inappropriate shock rates to $6.3 \%$ over 4 years (57) comparable to collectives including other structural heart diseases.

\section{Technical aspects and the totally subcutaneous ICD in ACHD}

A number of ACHD specific challenges may arise during implantation (Figure 1). In e.g., Ebstein anomaly and enlarged right ventricles (e.g., ToF) positioning of the right ventricular electrode may be troublesome or even not possible after valve surgery. Valve regurgitation may be significantly aggravated by implanted leads. Besides, concomitant venous abnormalities (e.g., left persistent superior cava) may be challenging for conventional transvenous lead positioning. Generally, transvenous ICD may be combined to epicardial or extracardiac parts of the system (either pacing and sensing or defibrillation component, see Figure 2). Extracardiac positioning of transvenous ICD and pacemaker parts has been the only technical option in univentricular conditions for decades. However, with approval of the totally S-ICD ${ }^{\circledR}$ these configurations are increasingly outdated.

The obvious advantages of the S-ICD ${ }^{\circledR}$ are of eminent value for ACHD. Despite the variable anatomy of congenital heart defects, efficacy and safety of the system has been proven in a variety of underlying disorders (3). The frequent occurrence of bundle branch block, intraventricular conduction delay and $\mathrm{T}$-wave abnormalities can hinder correct sensing of the device (Figure 3) as it uses three sensing vectors resembling surface ECG vectors. ACHD have a higher screening failure rate in the essential 


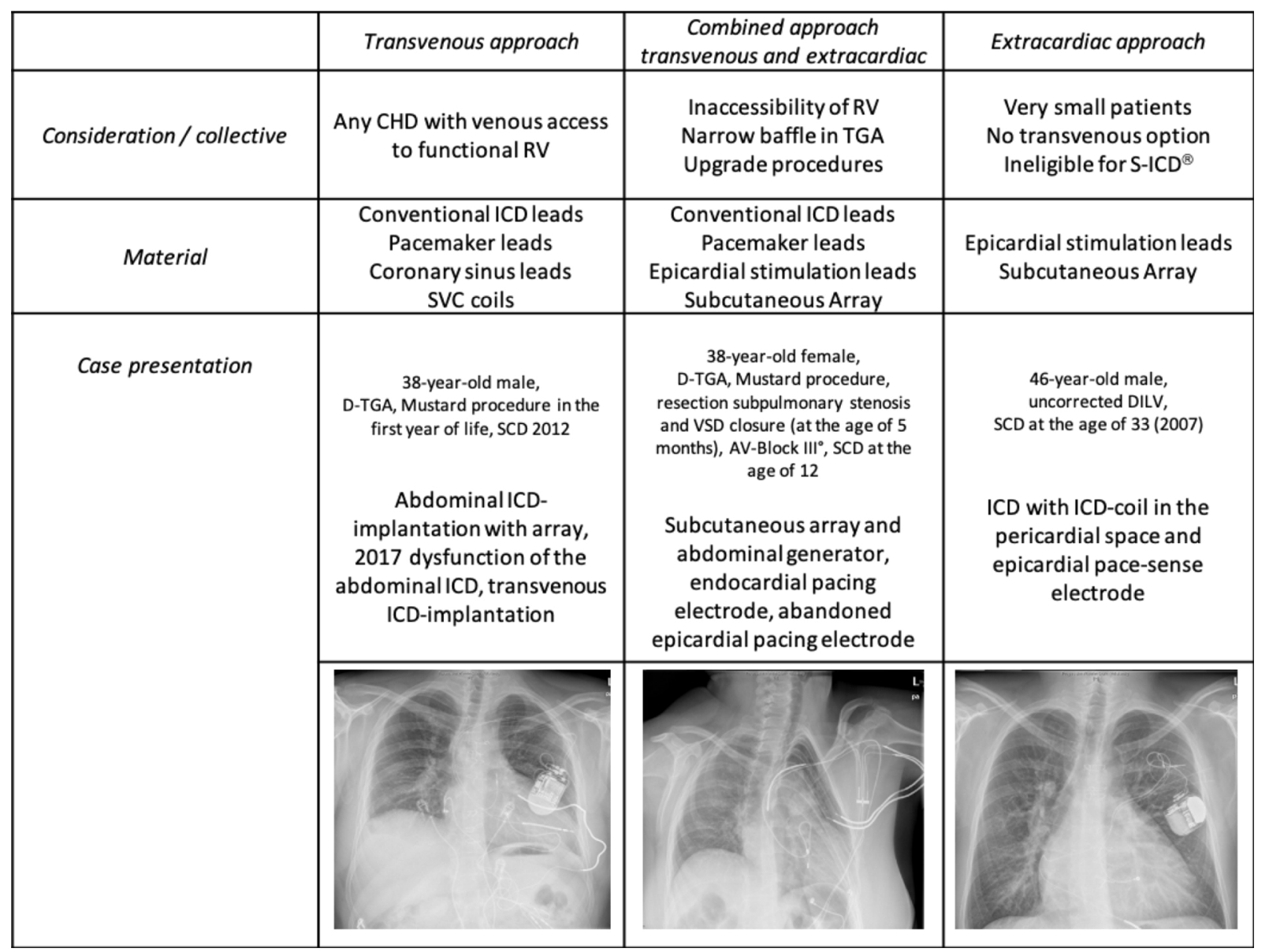

Figure 1 Technical options for conventional ICD-therapy in ACHD and case presentation. ICD, implantable cardioverter-defibrillator; RV, right ventricle; ACHD, adults with congenital heart disease; S-ICD ${ }^{\circledR}$, subcutaneous implantable cardioverter defibrillator; SVC, superior vena cava; TGA, transposition of the great arteries; DILV, double inlet left ventricle; SCD, sudden cardiac death.

simulation of the sensing vectors with a modified ECG prior to implantation (58) and right parasternal lead positioning may be necessary. Combination of either epicardial or endocardial pacemakers (see Figure 4) is possible but potential crosstalk of the devices with consecutive undersensing of ventricular fibrillation has to be considered. Combination of conventional pacemakers with a S-ICD ${ }^{\circledR}$ needs thorough intraoperative testing and knowledge on specific pacemaker features as automated self-programming into unipolar stimulation mode may occur in some devices.

\section{Conclusions}

In summary, risk stratification and ICD therapy in ACHD is a multidisciplinary mission. Patients will profit from collaboration between expert for ACHD, expert for cardiac imaging, pediatric cardiologists, surgeons, and electrophysiologists. Thorough knowledge of interventional techniques (e.g., baffle puncture, identification of critical slow-conduction isthmuses) and operation techniques in order to localize scars and reentry circuits is obligatory. This applies in equal measure to defibrillator therapy in patients with congenital heart defects. In some cases, unconventional technical solutions are mandatory. Of note, a sudden cardiac death risk score model for nine different congenital heart diseases is prospectively evaluating the implementation of seven risk factors (PREVENTIONACHD trial, NCT 03957824) (59). Hopefully, this ongoing research will allow more accurate risk stratification and individualized therapy in the near future. 


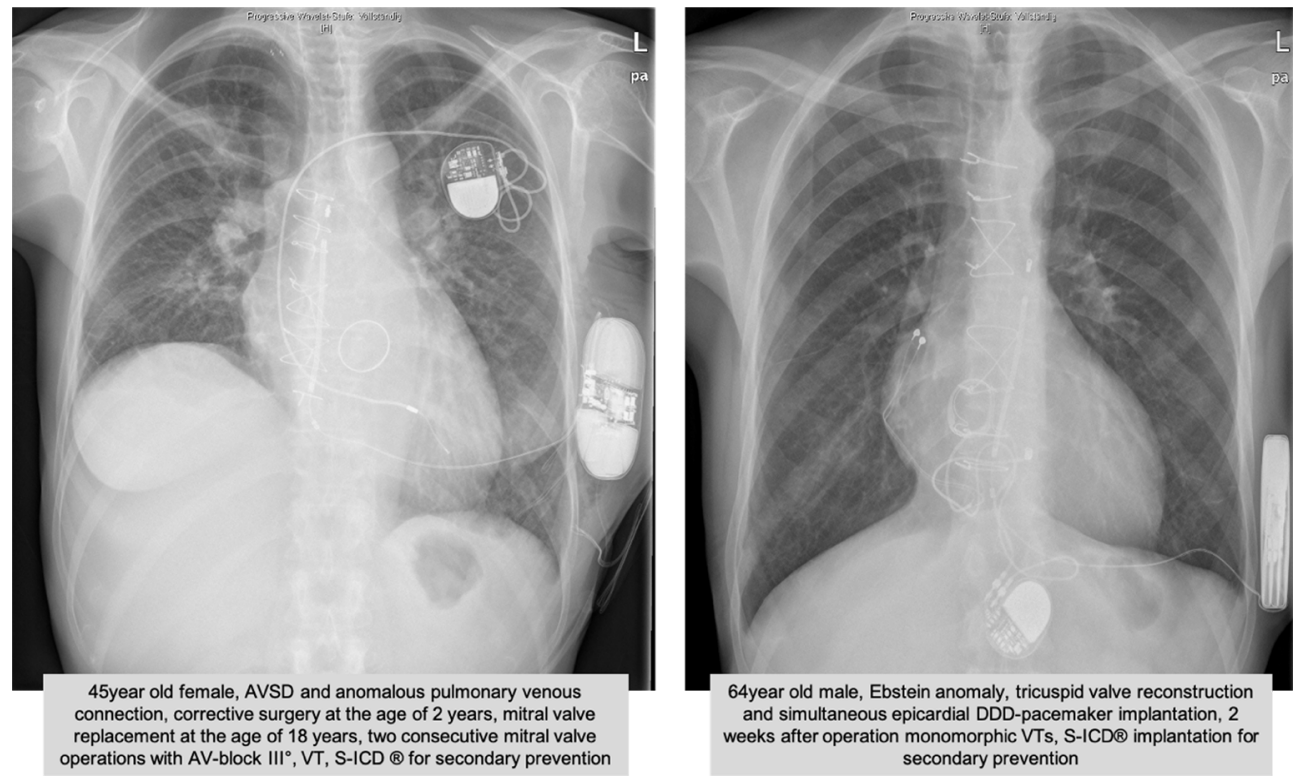

Figure 2 Case presentation of subcutaneous ICD therapy in combination to pacemaker (transvenous and epicardial) in ACHD with stimulation need. ACHD, adults with congenital heart disease; AVSD, atrioventricular septal defect; ICD, implantable cardioverterdefibrillator; V'T, ventricular tachycardia; S-ICD ${ }^{\circledR}$, subcutaneous implantable cardioverter defibrillator.

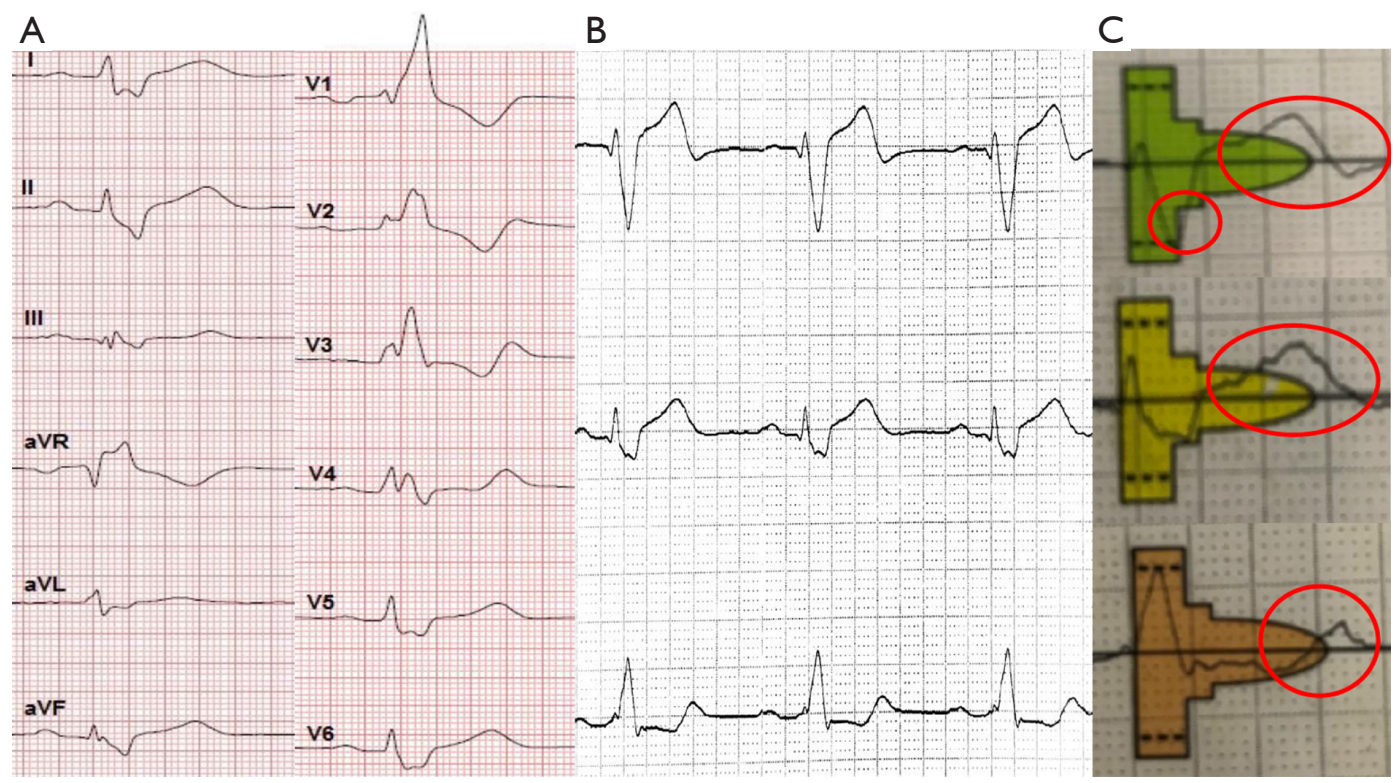

Figure 3 Case presentation of a 31-year-old patient after total repair of ToF with indication for an ICD. (A) 12-lead surface ECG showing a complete right bundle branch block with a QRS width of $180 \mathrm{msec}$. (B) Screening ECG for eligibility for a subcutaneous ICD system (simulation of the three screening vectors of the system by positioning ECG electrodes parallel to the sternum and in the left midaxillary line according to the later electrode and generator position). (C) A screening tool (comparable to ECG ruler) is positioned over the screening ECG. The screening ECG does not fit into the screening pattern (green, yellow and orange forms) leading to non-eligibility of all screening vectors for a subcutaneous ICD system, mostly because of the T-wave clearly exceeding the shape of the template indicated by the red circles. Implantation of a subcutaneous ICD in such a case bears a higher risk of inappropriate shocks due to T-wave oversensing. ICD, implantable cardioverter-defibrillator. 
INDUKTIONS-S-EKG: 24.03 .2017 15:11:38 25 mm/s 2.5 mm/mV

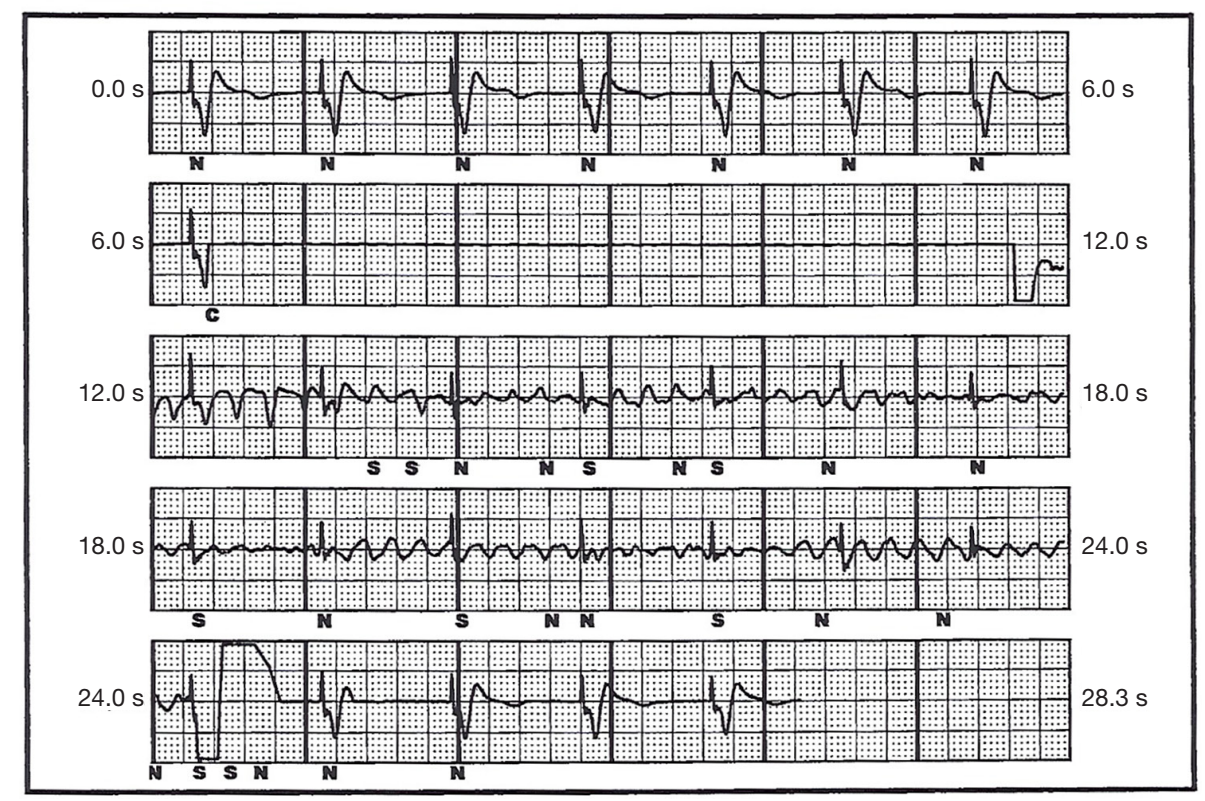

Figure 4 Tracing from an S-ICD ${ }^{\circledR}$ combined with a transvenous pacemaker, intraoperative testing of the system with crosstalk, undersensing of induced ventricular fibrillation by sensing of unipolar pacemaker spikes, termination of induced ventricular fibrillation by external defibrillation (last row). S-ICD ${ }^{\circledR}$, subcutaneous implantable cardioverter defibrillator.

\section{Acknowledgments}

Funding: None.

\section{Footnote}

Provenance and Peer Review: This article was commissioned by the Guest Editors (Yskert von Kodolitsch, Harald Kaemmerer, Koichiro Niwa) for the series "Current Management Aspects in Adult Congenital Heart Disease (ACHD): Part III" published in Cardiovascular Diagnosis and Therapy. The article has undergone external peer review.

Reporting Checklist: The authors have completed the Narrative Review reporting checklist. Available at http:// dx.doi.org/10.21037/cdt-20-633

Conflicts of Interest: All authors have completed the ICMJE uniform disclosure form (available at http:// dx.doi.org/10.21037/cdt-20-633). The series "Current Management Aspects in Adult Congenital Heart Disease (ACHD): Part III" was commissioned by the editorial office without any funding or sponsorship. Dr. HB reports other from Edwards Lifesciences, other from Actelion, outside the submitted work. The authors have no other conflicts of interest to declare.

Ethical Statement: The authors are accountable for all aspects of the work in ensuring that questions related to the accuracy or integrity of any part of the work are appropriately investigated and resolved.

Open Access Statement: This is an Open Access article distributed in accordance with the Creative Commons Attribution-NonCommercial-NoDerivs 4.0 International License (CC BY-NC-ND 4.0), which permits the noncommercial replication and distribution of the article with the strict proviso that no changes or edits are made and the original work is properly cited (including links to both the formal publication through the relevant DOI and the license). See: https://creativecommons.org/licenses/by-nc-nd/4.0/.

\section{References}

1. Khairy P, Van Hare GF, Balaji S, et al. PACES/HRS Expert Consensus Statement on the Recognition and Management of Arrhythmias in Adult Congenital Heart Disease: developed in partnership between the Pediatric 
and Congenital Electrophysiology Society (PACES) and the Heart Rhythm Society (HRS). Endorsed by the governing bodies of PACES, HRS, the American College of Cardiology (ACC), the American Heart Association (AHA), the European Heart Rhythm Association (EHRA), the Canadian Heart Rhythm Society (CHRS), and the International Society for Adult Congenital Heart Disease (ISACHD). Heart Rhythm 2014;11:e102-65.

2. Vehmeijer JT, Koyak Z, Budts W, et al. Prevention of Sudden Cardiac Death in Adults With Congenital Heart Disease: Do the Guidelines Fall Short? Circ Arrhythm Electrophysiol 2017;10:e005093.

3. Willy K, Reinke F, Bogeholz N, et al. The entirely subcutaneous ICDTM system in patients with congenital heart disease: experience from a large single-centre analysis. Europace 2019;21:1537-42.

4. van der Linde D, Konings EE, Slager MA, et al. Birth prevalence of congenital heart disease worldwide: a systematic review and meta-analysis. J Am Coll Cardiol 2011;58:2241-7.

5. Moons P, Engelfriet P, Kaemmerer H, et al. Delivery of care for adult patients with congenital heart disease in Europe: results from the Euro Heart Survey. Eur Heart J 2006;27:1324-30.

6. Khairy P, Ionescu-Ittu R, Mackie AS, et al. Changing mortality in congenital heart disease. J Am Coll Cardiol 2010;56:1149-57.

7. Engelings CC, Helm PC, Abdul-Khaliq H, et al. Cause of death in adults with congenital heart disease - An analysis of the German National Register for Congenital Heart Defects. Int J Cardiol 2016;211:31-6.

8. Diller GP, Kempny A, Alonso-Gonzalez R, et al. Survival Prospects and Circumstances of Death in Contemporary Adult Congenital Heart Disease Patients Under Follow-Up at a Large Tertiary Centre. Circulation 2015;132:2118-25.

9. Verheugt CL, Uiterwaal CS, van der Velde ET, et al. Mortality in adult congenital heart disease. Eur Heart J 2010;31:1220-9.

10. Marelli AJ, Mackie AS, Ionescu-Ittu R, et al. Congenital heart disease in the general population: changing prevalence and age distribution. Circulation 2007;115:163-72.

11. Gatzoulis MA, Balaji S, Webber SA, et al. Risk factors for arrhythmia and sudden cardiac death late after repair of tetralogy of Fallot: a multicentre study. Lancet 2000;356:975-81.

12. Khairy P, Landzberg MJ, Gatzoulis MA, et al. Value of programmed ventricular stimulation after tetralogy of fallot repair: a multicenter study. Circulation 2004;109:1994-2000.

13. Khairy P, Harris L, Landzberg MJ, et al. Implantable cardioverter-defibrillators in tetralogy of Fallot. Circulation 2008; 117:363-70.

14. Walsh EP. Sudden death in adult congenital heart disease: risk stratification in 2014. Heart Rhythm 2014;11:1735-42.

15. Gatzoulis MA, Till JA, Somerville J, et al. Mechanoelectrical interaction in tetralogy of Fallot. QRS prolongation relates to right ventricular size and predicts malignant ventricular arrhythmias and sudden death. Circulation 1995;92:231-7.

16. Bokma JP, Winter MM, Vehmeijer JT, et al. QRS fragmentation is superior to QRS duration in predicting mortality in adults with tetralogy of Fallot. Heart 2017;103:666-71.

17. Babu-Narayan SV, Kilner PJ, Li W, et al. Ventricular fibrosis suggested by cardiovascular magnetic resonance in adults with repaired tetralogy of fallot and its relationship to adverse markers of clinical outcome. Circulation 2006;113:405-13.

18. Diller GP, Kempny A, Liodakis E, et al. Left ventricular longitudinal function predicts life-threatening ventricular arrhythmia and death in adults with repaired tetralogy of fallot. Circulation 2012;125:2440-6.

19. Koyak Z, de Groot JR, Bouma BJ, et al. Symptomatic but not asymptomatic non-sustained ventricular tachycardia is associated with appropriate implantable cardioverter therapy in tetralogy of Fallot. Int J Cardiol 2013;167:1532-5.

20. Kapel GF, Sacher F, Dekkers OM, et al. Arrhythmogenic anatomical isthmuses identified by electroanatomical mapping are the substrate for ventricular tachycardia in repaired Tetralogy of Fallot. Eur Heart J 2017;38:268-276.

21. Baumgartner H, Bonhoeffer P, De Groot NM, et al. ESC Guidelines for the management of grown-up congenital heart disease (new version 2010). Eur Heart J 2010;31:2915-57.

22. Eapen ZJ, Al-Khatib S, Lopes RD, et al. Are racial/ethnic gaps in the use of cardiac resynchronization therapy narrowing?: an analysis of 107,096 patients from the National Cardiovascular Data Registry's ICD Registry. J Am Coll Cardiol 2012;60:1577-8.

23. Probst J, Diller GP, Reinecke H, et al. Prevention of sudden cardiac death in patients with Tetralogy of Fallot: Risk assessment and long term outcome. Int J Cardiol 2018;269:91-6. 
24. Zeppenfeld K, Schalij MJ, Bartelings MM, et al. Catheter ablation of ventricular tachycardia after repair of congenital heart disease: electroanatomic identification of the critical right ventricular isthmus. Circulation 2007;116:2241-52.

25. Moore JP, Seki A, Shannon KM, et al. Characterization of anatomic ventricular tachycardia isthmus pathology after surgical repair of tetralogy of Fallot. Circ Arrhythm Electrophysiol 2013;6:905-11.

26. Zeppenfeld K, Wijnmaalen AP. Clinical Aspects and Ablation of Ventricular Arrhythmias in Tetralogy of Fallot. Card Electrophysiol Clin 2017;9:285-94.

27. Vejlstrup N, Sorensen K, Mattsson E, et al. LongTerm Outcome of Mustard/Senning Correction for Transposition of the Great Arteries in Sweden and Denmark. Circulation 2015;132:633-8.

28. Flinn CJ, Wolff GS, Dick M 2nd, et al. Cardiac rhythm after the Mustard operation for complete transposition of the great arteries. N Engl J Med 1984;310:1635-8.

29. Sarkar D, Bull C, Yates R, et al. Comparison of longterm outcomes of atrial repair of simple transposition with implications for a late arterial switch strategy. Circulation 1999;100:II-176-81.

30. Kammeraad JA, van Deurzen CH, Sreeram N, et al. Predictors of sudden cardiac death after Mustard or Senning repair for transposition of the great arteries. J Am Coll Cardiol 2004;44:1095-102.

31. Gelatt M, Hamilton RM, McCrindle BW, et al. Arrhythmia and mortality after the Mustard procedure: a 30-year single-center experience. J Am Coll Cardiol 1997;29:194-201.

32. Buber J, Ackley TJ, Daniels CJ, et al. Outcomes following the implantation of cardioverter-defibrillator for primary prevention in transposition of the great arteries after intraatrial baffle repair: a single-centre experience. Europace 2016;18:1016-22.

33. Rhodes LA, Walsh EP, Gamble WJ, et al. Benefits and potential risks of atrial antitachycardia pacing after repair of congenital heart disease. Pacing Clin Electrophysiol 1995;18:1005-16.

34. Khairy P, Harris L, Landzberg MJ, et al. Sudden death and defibrillators in transposition of the great arteries with intra-atrial baffles: a multicenter study. Circ Arrhythm Electrophysiol 2008;1:250-7.

35. Chaix MA, Chergui M, Leduc C, et al. Sudden death in transposition of the great arteries with atrial switch surgery: Autopsy evidence of acute myocardial ischemia despite normal coronary arteries. Int J Cardiol 2019;288:65-7.
36. Schwerzmann M, Salehian O, Harris L, et al. Ventricular arrhythmias and sudden death in adults after a Mustard operation for transposition of the great arteries. Eur Heart J 2009;30:1873-9.

37. Khairy P, Clair M, Fernandes SM, et al. Cardiovascular outcomes after the arterial switch operation for D-transposition of the great arteries. Circulation 2013;127:331-9.

38. McCombe A, Touma F, Jackson D, et al. Sudden cardiac death in adults with congenitally corrected transposition of the great arteries. Open Heart 2016;3:e00407.

39. Connelly MS, Liu PP, Williams WG, et al. Congenitally corrected transposition of the great arteries in the adult: functional status and complications. J Am Coll Cardiol 1996;27:1238-43.

40. Koyak Z, Harris L, de Groot JR, et al. Sudden cardiac death in adult congenital heart disease. Circulation 2012;126:1944-54.

41. van der Bom T, Winter MM, Groenink M, et al. Right ventricular end-diastolic volume combined with peak systolic blood pressure during exercise identifies patients at risk for complications in adults with a systemic right ventricle. J Am Coll Cardiol 2013;62:926-36.

42. Hornung TS, Bernard EJ, Jaeggi ET, et al. Myocardial perfusion defects and associated systemic ventricular dysfunction in congenitally corrected transposition of the great arteries. Heart 1998;80:322-6.

43. Ghai A, Harris L, Harrison DA, et al. Outcomes of late atrial tachyarrhythmias in adults after the Fontan operation. J Am Coll Cardiol 2001;37:585-92.

44. Cecchin F, Johnsrude CL, Perry JC, et al. Effect of age and surgical technique on symptomatic arrhythmias after the Fontan procedure. Am J Cardiol 1995;76:386-91.

45. Sharma MS, Kostolny M, de Leval MR, et al. Surgical approaches for single ventricle palliation. Multimed Man Cardiothorac Surg 2007;2007:mmcts.2006.002394.

46. Poh C, Hornung T, Celermajer DS, et al. Modes of late mortality in patients with a Fontan circulation. Heart 2020;106:1427-31.

47. Czosek RJ, Anderson J, Khoury PR, et al. Utility of ambulatory monitoring in patients with congenital heart disease. Am J Cardiol 2013;111:723-30.

48. Attenhofer Jost CH, Tan NY, Hassan A, et al. Sudden death in patients with Ebstein anomaly. Eur Heart J 2018;39:1970-1977a.

49. Goldberg JF. Long-term Follow-up of "Simple" Lesions--Atrial Septal Defect, Ventricular Septal Defect, and Coarctation of the Aorta. Congenit Heart Dis 
2015;10:466-74.

50. Menting ME, Cuypers JA, Opic P, et al. The unnatural history of the ventricular septal defect: outcome up to 40 years after surgical closure. J Am Coll Cardiol 2015;65:1941-51.

51. Vehmeijer JT, Brouwer TF, Limpens J, et al. Implantable cardioverter-defibrillators in adults with congenital heart disease: a systematic review and meta-analysis. Eur Heart J 2016;37:1439-48.

52. Coutinho Cruz M, Viveiros Monteiro A, Portugal G, et al. Long-term follow-up of adult patients with congenital heart disease and an implantable cardioverter defibrillator. Congenit Heart Dis 2019;14:525-33.

53. Bardy GH, Lee KL, Mark DB, et al. Amiodarone or an implantable cardioverter-defibrillator for congestive heart failure. N Engl J Med 2005;352:225-37.

54. Yap SC, Roos-Hesselink JW, Hoendermis ES, et al. Outcome of implantable cardioverter defibrillators in adults with congenital heart disease: a multi-centre study. Eur Heart J 2007;28:1854-61.

55. Gleva MJ, Wang Y, Curtis JP, et al.. Complications Associated With Implantable Cardioverter Defibrillators in Adults With Congenital Heart Disease or Left Ventricular
Noncompaction Cardiomyopathy (From the $\operatorname{NCDR}((\mathrm{R})$ ) Implantable Cardioverter-Defibrillator Registry). Am J Cardiol 2017;120:1891-8.

56. Berul CI, Van Hare GF, Kertesz NJ, et al. Results of a multicenter retrospective implantable cardioverterdefibrillator registry of pediatric and congenital heart disease patients. J Am Coll Cardiol 2008;51:1685-91.

57. Goldstein SA, LaPage MJ, Dechert BE, et al. Decreased inappropriate shocks with new generation ICDs in children and patients with congenital heart disease. Congenit Heart Dis 2018;13:413-8.

58. Okamura H, McLeod CJ, DeSimone CV, et al. Right Parasternal Lead Placement Increases Eligibility for Subcutaneous Implantable Cardioverter Defibrillator Therapy in Adults With Congenital Heart Disease. Circ J 2016;80:1328-35.

59. Vehmeijer JT, Koyak Z, Zwinderman AH, et al. PREVENTION-ACHD: PRospEctiVE study on implaNTable cardioverter-defibrillator therapy and suddeN cardiac death in Adults with Congenital Heart Disease; Rationale and Design. Neth Heart J 2019;27:474-9.
Cite this article as: Köbe J, Willy K, Eckardt L, Baumgartner H, Wasmer K. Narrative review of: risk stratification and implantable cardioverter-defibrillator therapy in adults with congenital heart disease. Cardiovasc Diagn Ther 2021;11(2):538-549. doi: /10.21037/cdt-20-633 